\title{
PROTAGONISMO SOCIAL E MEDIAÇÃO DA INFORMAÇÃO
}

\author{
Henriette Ferreira Gomes ${ }^{1}$
}

UFBA

\begin{abstract}
Resumo
Abordagem do protagonismo social, analisando sua relação com a informação, concluindo pela compreensão deste como objetivo do trabalho informacional, situando a mediação da informação como sua ação central. Parte da apresentação das origens conceituais em torno do protagonismo, buscando, à medida que debate as referências acerca do tema, demonstrar a relação do desenvolvimento do protagonismo social com o trabalho informacional, assim como sua posição de meta da atividade da mediação da informação, executada nas suas cinco dimensões e na condição de elemento central desse trabalho. As assertivas apresentadas são resultado do estudo crítico da bibliografia da área da Ciência da Informação que aborda o protagonismo e a mediação da informação, assim como de estudos de filósofos e pensadores que abordam os aspectos sociais e políticos da comunicação e da formação de sujeitos socialmente ativos, permitindo a identificação das relações entre protagonismo e mediação da informação, como também que a mediação consciente favorece o primeiro, concluindo que o apoio ao seu desenvolvimento representa a principal responsabilidade social do trabalho com a informação.
\end{abstract}

Palavras-chave: Protagonismo social. Mediação da informação. Dimensões da Mediação da Informação.

\section{SOCIAL PROTAGONISM AND MEDIATION OF INFORMATION}

\begin{abstract}
Approach the social protagonism, analyzing its relation with the information, concluding for the understanding of this as an objective of the informational work, locating the mediation of information as its central action. Part of the presentation of the conceptual origins around the protagonism, seeking, as it debates the references on the subject, to demonstrate the relation of the development of the social protagonism with the informational work, as well as its position of goal of the activity of the information mediation, executed in its five dimensions and as the central element of this work. The assertions presented are the result of the critical study of the bibliography of the area of Information Science that addresses the protagonism and mediation of information, as well as studies of philosophers and thinkers that address the social and political aspects of communication and the formation of socially active subjects, allowing the identification of the relations between protagonism and mediation of information, but also that the conscious mediation favors the first one, concluding that the support to its development represents the main social responsibility of the work with the information
\end{abstract}

Keywords: Social protagonism. Mediation of information. Dimensions of mediation of information.

1 Professora titular do ICI e PPGCI/ UFBA. Doutora em Educação. 


\section{INTRODUÇÃO}

Para abordar o protagonismo social, analisando sua relação com a informação, situa-se a mediação como ação central que coloca a informação em favor do desenvolvimento do protagonismo.

As reflexões expostas resultaram de uma análise crítica da bibliografia da Ciência da Informação que trata do protagonismo e das suas relações com a cultura e a com a informação, suas implicações para a mediação da informação, envolvendo as dimensões da própria ação mediadora. A análise dessa parte da bibliografia foi articulada a análise de estudos produzidos por filósofos e pensadores que abordam a complexidade social, seus sistemas e processos de comunicação, tal como o processo de formação do sujeito social, crítico e criativo.

O debate estabelecido entre as referências analisadas permitiu demonstrar a relação do trabalho informacional com o desenvolvimento do protagonismo social, como também a posição deste como meta da atividade da mediação da informação. Tal meta é alcançada na medida em que esta é realizada na consecução e articulação de suas cinco dimensões, o que coloca a mediação da informação na condição de elemento central do trabalho informacional.

As relações entre protagonismo social e mediação da informação sinalizam que o primeiro pode ser favorecido pela realização consciente da ação mediadora, o que evidencia o apoio desta a esse desenvolvimento, ganhando status nuclear no âmbito da relação entre a responsabilidade social do trabalho com a informação.

Para exposição das reflexões produzidas neste estudo, o texto se organiza pela abordagem em torno da gênese conceitual, que sustenta o sentido de protagonismo para, na sequência, apresentar as relações com a mediação da informação, em suas cinco dimensões, concluindo que esta tem o papel de apoiar o desenvolvimento do protagonismo social, consistindo em elemento fundante do cumprimento da responsabilidade social da área da informação.

\section{COMPREENDENDO O PROTAGONISMO}

O protagonismo representa, em sua essência, uma ação de resistência contra a opressão, discriminação, apartheid social, rejeição, desrespeito e negação ao diferente, por esta razão, não se pode falar em protagonismo, omitindo-se que este ao mesmo que resulta da ação mediadora também a impulsiona e, por conseguinte, também reflete na dimensão política desta ação. 
Compreendendo que o protagonismo social envolve diversas dimensões do protagonismo, a abordagem de protagonismo cultural de Perrotti convida à expansão do olhar em torno deste. Perrotti (2017, p. 15) assinala que

[...] protagonismo implica uma dimensão existencial inextricável. Significa resistência, combate, enfrentamento de antagonismos produzidos pelo mundo físico e/ou social e que afeta a todos. Significa tomada de posição dianteira face a obstáculos que ameaçam a espécie (causados por pessoas, animais, circunstâncias, sentimentos, ideias, preconceitos etc.).

Nesse sentido o protagonismo é social, isto é, é uma conduta, uma postura, um modo de existência que envolve todas as esferas da vida humana, nas suas diversas dimensões, incluindo a dimensão cultural, compreendendo-se cultura como produção humana, na qual se inclui o objeto informação.

Voltando o olhar às raízes da concepção do protagonismo, encontra-se nos estudos de Perrotti (2017) a gênese conceitual na obra de Sófocles (496-409 a.C.) que se apresenta na encarnação da resistência/consciência em Antígona. Ao tomar conhecimento da morte de seus dois irmãos, em batalhas, tendo um deles sido discriminado e violentamente tratado com a proibição do seu sepultamento, ficando seu corpo exposto ao ataque de aves de rapina, em razão de em vida ter se colocado como opositor do Rei Creonte de Tebas, Antígona se ergue, reage e enfrenta uma luta corajosa e resiliente pelo sepultamento, argumentando junto ao rei que as leis dos deuses regentes da vida na pólis colocavam o sepultamento como um direito de todos os cidadãos, independentemente de seus atos. Mas o Rei Creonte, movido pelo ódio e autoritarismo, ignora seus argumentos, ultrajando as próprias leis vigentes. E, na regência do ódio que sentira por ter sido desafiado, sepulta Antígona com vida em uma caverna subterrânea.

Claramente observa-se na história de Sófocles a luta entre o público e o privado, entre a negação e a compaixão ao outro, entre atos arbitrários e solidários, a luta entre a busca do controle que impõe silêncio e subserviência e a resistência consciente pelo lugar do coletivo, potencialmente transformadora da realidade. Nesse confronto, o protagonista resiste porque não há para ele outra ação possível, residindo aqui sua força política, que é transformadora e, portanto, assustadora ao opressor.

Por outro ângulo, a personagem de Sófocles nos traz ainda a reflexão de que o protagonista, ao se levantar e lutar, provoca reações contrárias, adversas e, muitas vezes, arbitrárias. No entanto, por ser um protagonista, compreende o caráter político da sua ação, se mantendo na resistência potencialmente transformadora. Ressalta-se que a resistência guarda em si um potencial para a transformação, que pode ou não ocorrer imediatamente à ação de resistência. Na obra de Sófocles, Creote, ao não aceitar os argumentos de Antígona e ao ultrajar 
as próprias leis de Tebas, colocou a esfera do privado (das suas paixões) em um plano superior ao da esfera pública, levando Tebas a um período de escuridão e de grande violência, o que comprometeu a vida coletiva, as relações entre os diferentes e o respeito à alteridade, desestabilizando as bases sustentadoras da vida social. Em oposição a esta conduta, colocou-se Antígona em defesa da esfera pública, ainda que sua ação de resistência não tenha resultado em transformação imediata. Mas, a Antígona não restava alternativa que não a de se colocar frontalmente contra a arbitrariedade, trazendo em sua tomada de posição a essência do conceito de protagonismo, que está relacionado à valorização da vida cidadã, na qual é imprescindível o respeito ao outro, ao diferente, ainda que nesta luta não se apresente a vitória de imediato.

Perrotti (2017) alerta para a perda do sentido primeiro de protagonismo, com o emprego largo que se faz atualmente desse termo em diferentes áreas da ação social. Para ele trona-se relevante resgatar o sentido originário na obra de Sófocles, onde protagonista é o principal lutador $($ proto $=$ primeiro, principal $)$ associado à agonistes (o que luta, lutador $)$. Assim, em sua raiz conceitual, protagonismo se relaciona à conduta de resistência e combate, de enfrentamento de antagonismos (que lutam contra) que afetam a todos na sociedade.

O protagonismo só existe na tomada de posição. Protagonistas assumem ações de liderança, se colocam contra obstáculos que representem ameaça ao coletivo, assumem embates pela construção de um mundo em favor do bem comum. Ser protagonista implica na tomada de posição de sujeito social ativo, que age e reage com e em relação ao outro (presente ou não na cena da ação). Enfim, o protagonista é aquele que age, que reage, que se ergue, que se coloca em relação aos interesses do coletivo.

Outra característica importante do protagonista é a de considerar mais importante que derrotar o adversário e vencer a luta, a afirmação dos princípios do viver junto, do respeito aos direitos sociais, da justiça social. Conforme Perrotti (2017), para o protagonista importa reagir, lutar e superar o fazer vazio e sem significação, e nesta perspectiva nos lembra também o autor da mitologia grega, que traz por meio da história de Sísifo um símbolo da luta de resistência contra a vida sem sentido. Sísifo, por ter vivido uma vida pouco convencional, foi condenado pelos deuses a carregar uma pedra até o topo de uma montanha, para ali equilibrá-la. Tal castigo tornara-se permanente, já que ao atingir o topo, a pedra voltava a descer montanha abaixo. No mito de Sísifo a pena do trabalho inútil, sem reconhecimento social e retorno compensatório ganha centralidade. No entanto, Sísifo, na atitude protagonista de não aceitar a vida sem sentido, encontra, no seu esforço de retornar com a pedra ao topo, sua autoconsciência, reconhecendo sua força interior, superior a do rochedo que tenta vencer. Apesar da dor, do cansaço, da infelicidade imposta, ele resiste e insiste em erguer novamente a pedra em direção ao topo da 
montanha, encontrando o sentido de sua vida na capacidade de resistir e insistir. Sísifo encontra em si a essência da resistência, encontrando nesse ponto a sua própria felicidade, dando sentido ao trabalho inútil que lhe fora imposto. Assim Sísifo torna-se forte, no âmbito da sua consciência, rebelando-se contra o destino imposto, erguendo-se na condição de protagonista e abandonando a condição de vítima no cumprimento de uma pena injusta, posicionando-se, por fim, como um agente transformador do seu próprio sentido de viver.

Nessa linha reflexiva, identifica-se também o agir como elemento mobilizador da transformação, já que o protagonismo exige a tomada de posição. Para Arendt (2007) o agir já significa em si uma tomada de posição e iniciativa, imprimindo movimento a algo. A perspectiva de Arendt dialoga com a assertiva de Perrotti (2017, p, 15) de que

“[...] protagonistas assumem a luta pela construção, pela criação, como atitude face ao mundo. Lutar, mais que enfrentamento 'contra', é modo de ser e de estar, de produzir e cuidar de um mundo comum, habitável e convivial."

Assim, pode-se defender que o protagonismo é social, além de representar uma conduta assumida, uma postura, um modo de ser e estar no mundo, que envolve as diversas esferas e dimensões da vida social, incluindo a dimensão cultural, compreendendo-se cultura como produção humana, na qual se inclui o objeto informação.

O trabalho informacional se conecta ao processo do desenvolvimento do protagonismo social. Se o desenvolvimento do protagonismo é depende do processo de autoconhecimento, gerador da tomada de posição frente aos obstáculos socialmente impostos, o lócus da informação que expressa o conhecimento, torna-se evidenciado.

Conceituando informação como conhecimento em estado de compartilhamento Gomes $(2016,2017)$ ressalta a natureza social da informação, resultante do processo dialógico que sustenta e subsidia a geração do conhecimento, por potencializar a capacidade humana de interpelar, de interferir, de criar e recriar o próprio conhecimento anteriormente instituído e o próprio mundo. Sendo assim, qualquer conhecimento ou autoconhecimento é dependente do compartilhamento do que já se pôde conhecer. Como defende Brait (2001), os sujeitos sociais se constituem e constituem no processo de interação a partir do qual se torna possível a construção de sentido.

O processo interacionista, colaborativo e de compartilhamento, implica em várias ações de mediação, e dentre elas a própria mediação da informação. Mediadores e dispositivos de mediação são articulados e atuam como elementos importantes ao conhecer. Nessa perspectiva evidencia-se que a informação é, ao mesmo tempo, resultado e subsídio ao compartilhamento. 
Ela é produzida, organizada, acessada, utilizada e apropriada no processo de encontro com o outro, residindo ai seu caráter alteritário. (GOMES, 2016, 2017).

Em seu conceito de informação como conhecimento em estado de compartilhamento, Gomes $(2016,2017)$ chama atenção de que a informação caracteriza-se como produto gerado no esforço de colocar em comum e, também, elemento mobilizador da ação de comunicar, por permitir o acesso ao conhecimento (que se encontra em estado materializado), com potência impulsionadora de outras ações de comunicação, a partir das quais novas revisões e indagações podem emergir, potencializando a geração de novos conhecimentos.

Assim, o próprio caráter social da informação, que resulta da ação humana de colocar em comum, de compartilhar, de busca do encontro com o outro, que a retomará em outro agir, em outra ação e reação, sinalizando que esse movimento informacional constitui-se em contributo ao nascimento da ação e comportamento protagonista.

No protagonismo social assegura-se o espaço político da interação, da troca e da intersubjetividade. Como defende Arendt (2007), a ação é movimento e condição de preservação do espaço político que sustenta o exercício da crítica, interpelação, negociação, articulação e acordo entre os sujeitos sociais.

Destacando que a interação é uma esfera do social, Habermas (1987) nos lembra que nela se dá a convivência, a comunicação e a ação entre os sujeitos sociais, na busca do entendimento e do consenso possível para a transformação das coisas do mundo do sistema e do mundo da vida. Na interação ocorre a intersubjetividade, e a possibilidade de se reconhecer e questionar as pretensões de validade das manifestações, a partir do que se pode provisoriamente estabelecer o que seja verdade.

Ao compreender informação como conhecimento em estado de compartilhamento, Gomes $(2016,2017)$ ressalta sua qualidade de ação e de instância do colocar em comum o quê se sabe, sente e pensa, o coloca a informação na condição daquilo que potencialmente pode mover a tomada de posição e, ao mesmo tempo, como resultante de uma posição anterior de compartilhamento. Assim, esse conceito de informação se aproxima das abordagens de Arendt (2017), que destaca a importância da ação, da tomada de posição, e de Habermas (1987), quando este ressalta o valor social da ação comunicativa. Na interseção dessas três abordagens fica mais clara a conexão entre protagonismo e informação. Por outro lado, de tal perspectiva emerge a questão quanto à posição da mediação nessa relação entre protagonismo e informação. 


\section{MEDIAÇÃO DA INFORMAÇÃO E DESENVOLVIMENTO DO PROTAGONISMO SOCIAL}

Ao tratar da mediação, retoma-se Orozco Gómez (2000) e Bakhtin (1981). Enquanto Orozco Gómez (2000) define a mediação como lócus de geração de sentido no processo de comunicação no interior de determinada cultura, Bakhtin (1981) assinala que é no âmbito da cultura que os signos são construídos. A consciência e capacidade de desenvolver compreensão emergem do substrato semiótico produzido nas relações sociais, que se manifestam tanto no âmbito da intra quanto da intersubjetividade, expressas na articulação de diversos signos e linguagens. (BAKHTIN, 1981).

As perspectivas de mediação de Orozco Gómez e Bakhtin a colocam em grande aproximação com as abordagens da mediação de informação no contexto da Ciência da Informação, por compreendê-la como impulsionadora da geração de sentidos, sentidos que se expressam na instância do conhecimento em estado de compartilhamento (informação).

Qualquer tipo de mediação, mas em especial a mediação da informação se caracteriza como um processo que se dá na interrelação de elementos técnicos, humanos, ambientais e semiológicos. Esses elementos são articulados, possibilitando tanto a produção quanto o compartilhamento do conhecimento. No entanto, Gomes $(2014,2016)$ alerta que a efetividade da mediação da informação ocorre por meio de cinco dimensões identificadas em seus estudos. A autora defende que essas cinco dimensões da mediação da informação, se articuladas e alcançadas, tornam a mediação efetiva e propulsora do protagonismo social.

Para Gomes (2014, 2016, 2017), apenas ao alcançar as cinco dimensões em articulação, a mediação pode contribuir para o processo de apropriação da informação, sem a qual o desenvolvimento do protagonismo pode ser comprometido ou postergado. Segundo a autora, a tomada de posição frente a todo e qualquer problema é dependente da apropriação da informação pelos sujeitos sociais. A apropriação da informação é sustentáculo do processo de conscientização, de domínio do conhecimento e de exercício da crítica, elementos essenciais à constituição do sujeito protagonista.

A mediação da informação é dependente das práticas de comunicação. Ocupando-se da transmissão cultural e dos processos de compartilhamento por meio dos quais os sujeitos podem gerar significações, a mediação da informação tem uma dimensão dialógica. A partir do processo dialógico ocorre o encontro, a manifestação e a interlocução entre diferentes sujeitos sociais. No exercício consciente da mediação da informação, o processo dialógico favorecerá o exercício da crítica e a observação mais intensa e precisa das incompletudes e lacunas dos 
conhecimentos instituídos e estabilizados, assim como da complexidade dos fenômenos, sejam eles sociais ou naturais.

Por outro lado, no exercício da crítica o sujeito tem a possibilidade de alcançar o autoconhecimento, que tornará mais claros seus próprios limites e potencialidades, o que expande a probabilidade do desenvolvimento de estratégias e comportamentos para superação desses limites, como também de exploração dessas potencialidades. Nessa conquista, o sujeito informacional alcançará o prazer estético, pelo reconhecimento da beleza do conhecimento construído, da apropriação e da geração de novos conhecimentos, o que evidencia outra dimensão estabelecida por Gomes $(2014,2016)$, que é a dimensão estética da mediação da informação.

Mas, no cerne desse processo criador situa-se a ação consciente da busca do autoconhecimento, que remete à disponibilidade para o encontro com a diversidade e o respeito à alteridade. $\mathrm{O}$ processo de autoconhecimento demanda disposição para conhecer o outro, conhecer o meio e o contexto, já que nos constituímos como sujeitos a partir da interação com estes. Desse modo, observa-se a interligação da dimensão estética à dimensão ética da mediação da informação. (GOMES. 2014, 2016).

A dimensão ética da mediação da informação exige do profissional a realização da ação mediadora em postura de abertura e acolhimento ao diferente. A dimensão ética demanda o ouvir e dialogar com o outro, com ampliação da capacidade de escuta e observação sensíveis. Também reclama a adoção de princípios capazes de inibir a censura e o acesso à informação em desrespeito ao diferente, ao livre pensar e aos direitos sociais.

Considerando o alerta de Almeida Junior $(2008,2009)$ de que a mediação da informação pode também ser entendida como uma ação de interferência, os riscos da relação tênue entre as ações de interferência e de manipulação ficam evidenciados. Frente a esses riscos conclui-se pela extrema necessidade de se defender a expansão e o fortalecimento da ação mediadora consciente, como esforço de eliminar ou reduzir significativamente a violação da ética no trabalho informacional.

A mediação consciente deve ser construída pela área da informação, como elemento fundamental para se alcançar os resultados projetados pelo campo quanto ao cumprimento da sua responsabilidade social, mas também como um mecanismo de desenvolvimento mais efetivo da mediação, assim como de inibição de condutas antiéticas no fazer informacional.

A consciência e a competência para interferir evitando a manipulação são dependentes da conduta ética associada à busca de identificação de sinais que indiquem o grau de conforto, confiança, cumplicidade e cooperação que se pode gerar na ação mediadora. (GOMES, 2016, p. 103). 
Por outro lado, observa-se que de um modo geral, as atividades de mediação da informação guardam um caráter formativo pela forte relação da mediação com a estética e a ética. Este caráter motiva a realização de atividades de formação do usuário, como também de qualificação profissional, que evidenciam mais claramente as dimensões estética, formativa e ética da mediação da informação. No entanto, ressalta-se que mesmo não ocorrendo atividades planejadas e sistematizadas de formação e qualificação, o próprio encontro com o conhecimento em estado de compartilhamento (informação) é potencializador da formação e da qualificação. Em essência, toda atividade humana tem um caráter formativo, já que no fazer, no movimento e na ação acaba-se por inventar ou reinventar essas e outras ações, repercutindo também em transformações dos próprios sujeitos sociais. Conforme Larrosa (2002), a experiência é tudo que se vivência, tudo que acontece ao sujeito, tudo que o toca e o afeta, enfim, o que mobiliza o sujeito. Na experiência o sujeito se recria e recria o mundo, assim, a mediação da informação que mobiliza a experiência criativa atua na dimensão formativa.

Ao se analisar as quatro dimensões da mediação da informação inicialmente defendidas por Gomes (2014), observa-se como objetivo implícito dessa mediação o desenvolvimento do protagonismo social. Por meio do processo dialógico pode se dar a aproximação entre agentes e dispositivos de informação, colocando-se também em relevo a própria condição de protagonista do agente mediador, já que este age, constrói e interfere no meio, carregando em si a característica de protagonista social, de um sujeito da estética, da ética e da produção humanizadora do mundo. Neste sentido, o mediador da informação caracteriza-se como um agente político. A partir dessa reflexão Gomes $(2016,2017)$ expandiu o leque das dimensões da mediação da informação, passando a defender a existência de uma quinta dimensão, que é a dimensão política. A mediação da informação, se realizada com consciência, alcança sua dimensão politica, de fundamental importância para sua efetividade. Como defende Freire (2008), a consciência fortalece no sujeito sua potência transformadora de si e do mundo.

Assim, no fazer informacional torna-se imprescindível a reflexão e a consciência acerca das dimensões dialógica, estética, formativa, ética e política da mediação da informação. Quando na concepção, planejamento e execução das atividades de mediação da informação, é considerado o espectro conceitual e as dimensões da mediação, amplia-se a possibilidade de resultados qualitativos no desenvolvimento do protagonismo social.

Isso implica na propositura da atitude protagonista do próprio sujeito que realiza a mediação da informação. Não se tem efetivamente mediação da informação em favor do desenvolvimento do protagonismo social sem a sua execução consciente. Tomando-se como 
referência o conceito de mediação da informação de Almeida Junior (2015), observa-se a relevância de se avançar na realização de uma mediação mais consciente da informação, o que colocará cada vez mais em evidência as relações entre informação e protagonismo social.

Há emergência na ampliação das discussões direcionadas ao imprescindível desenvolvimento de uma consciência profissional quanto à centralidade consistente que a mediação da informação ocupa tanto no fazer profissional, no âmbito micro social, quanto no cumprimento da responsabilidade social do seu campo do conhecimento, em um âmbito macro social. Esta consciência alcançada e assumida colocará o profissional e a área da informação diante de um caminho socialmente promissor e responsável.

\section{CONSIDERAÇÕES FINAIS}

O protagonismo social se caracteriza como elemento fundante do processo democrático de construção das bases de humanização do mundo e, o efetivo desenvolvimento desse protagonismo se dá com o apoio das atividades de mediação consciente da informação, o que implica no conhecimento do que seja informação, da sua missão social, das dimensões da mediação e da força dessa ação também protagonista.

A informação, na condição de conhecimento em estado de compartilhamento, situa-se na base da construção de todos os saberes e culturas, se caracterizando como substrato e, ao mesmo tempo, produto das partilhas que se efetivam nas relações sociais, o que a caracteriza como produto do social. Em qualquer domínio do conhecimento ou campo da cultura, a informação é elemento que, interpretado e significado, torna possível a compreensão da realidade e das possibilidades de transformação desta.

O trabalho consciente com a informação coloca o protagonismo social e a mediação na centralidade deste fazer. A consciência de que o trabalho informacional de preservação da memória social; do desenvolvimento das atividades de acesso e uso da informação; de construção do espaço dialógico; crítico e criativo, promotores do processo de apropriação da informação, evidencia o protagonismo como meta central do trabalho com a informação, assim como a mediação da informação e suas dimensões como fundamentos que sustentam a efetividade deste fazer humano no que tange a sua responsabilidade social. 


\section{REFERENCIAS}

ALMEIDA JÚNIOR, Oswaldo Francisco de. La mediación de la información y la lectura informacional. In: GARCIA MARCO, Francisco Javier (Org.). Avances y perspectivas en sistemas de información y documentación. Zaragoza: Universidad de Zaragoza, 2009. p. 23-28.

ALMEIDA JÚNIOR, Oswaldo Francisco de. Mediação da informação: um conceito atualizado. In: BORTOLIN, Sueli; SANTOS NETO, João A. dos; SILVA, Rovilso J. da (Orgs.). Mediação oral da informação e da leitura. Londrina: ABECIN, 2015. P. 9-32.

ALMEIDA JÚNIOR, Oswaldo Francisco de; BORTOLIN, Sueli. Mediação da informação e da leitura. In: SILVA, Terezinha Elisabeth da (Org.).

Interdisciplinaridade e transversalidade em Ciência da Informação. Recife: Néctar, 2008, p.67-86.

AMERICAN LIBRARY ASSOCIATION (ALA). Presidential Committee on Information Literacy. Final report. 1989. Disponível em: <http://www.ala.org./ala/acrl/acrlpubs/whitepapers/presidential.cfm>. Acesso em: 14 set. 2011.

ARENDT, Hanna. A condição humana. 10. ed. Rio de Janeiro: Forense Universitária, 2007. BAKTHIN, M. Marxismo e filosofia da linguagem. São Paulo: Hucitec, 1981.

BRAIT, Beth. O processo interacional. In: PRETI, Dino (Org.). Análise de textos orais. 5. ed. São Paulo: Humanitas, 2001. cap. 9, p. 189-214.

DAHLET, Patrick. Dialogização enunciativa e paisagens do sujeito. In: BRAIT, Beth (Org.). Bakhtin, dialogismo e construção do sentido. Campinas: Unicamp, 1997. p. 59-87.

FREIRE, Paulo. Conscientização: teoria e prática da libertação: uma introdução ao pensamento de Paulo Freire. São Paulo: Centauro, 2008.

GOMES, Henriette Ferreira. Comunicação e informação: relações dúbias, complexas e intrínsecas. In: MORIGI, Valdir; JACKS, Nilda; GOLIN, Cida. (Orgs.). Epistemologias, comunicação e informação. Porto Alegre: Sulina, 2016. P. 91-107.

GOMES, Henriette Ferreira. A dimensão dialógica, estética, formativa e ética da mediação da informação. Informação \& Informação, Londrina, v. 19, n. 2, p. 46-59, maio./ago. 2014. Disponível em: <http://www.uel.br/revistas/uel/index.php/informacao/article/view/19994>. Acesso em: 12 set. 2014.

GOMES, Henriette Ferreira. Mediação da informação e protagonismo social: relações com vida ativa e ação comunicativa à luz de Hannah Arendt e Jürgen Habermas. In: GOMES, Henriette Ferreira; NOVO, Hildenise Ferreira (Orgs.). Informação e protagonismo social. Salvador: EDUFBA, 2017. P. 27-44. 
HABERMAS, J. Teoria de la acción communicativa II: crítica de la razón funcionalista. Madrid: Taurus, 1987.

HABERMAS, Jürgen. Teoria de la acción comunicativa I: racionalidade de la acción y racionalización social. Madrid: Taurus, 1987.

LARROSA, J. Nietzsche \& a educação. Belo Horizonte: Fundação Biodiversitas: Autêntica, 2002.

OROZCO GOMEZ, G. La investigación en comunicación desde la perspectiva cualitativa. México: Universidade Nacional de la Plata, 2000.

PERROTTI, Edmir. Sobre informação e protagonismo cultural. In: GOMES, Henriette Ferreira; NOVO, Hildenise Ferreira (Orgs.). Informação e protagonismo social. Salvador: EDUFBA, 2017. p. 11-26. 